\title{
Elevação da Vogal Átona Final /O/ em Jrati, Paraná
}

\author{
Lucelene Teresinha FRANCESCHINI* \\ Loremi LOREGIAN-PENKAL**
}

* Doutora em Letras/Sociolinguística pela Universidade Federal do Paraná (2011), com pós-doutorado na área. Professora Colaboradora na Universidade Estadual do Centro-Oeste, Irati, Paraná. Contato: lucelenetf@gmail.com

** Doutora em Letras/Sociolinguística pela Universidade Federal do Paraná (2004), com pós-doutorado na área. Docente da Universidade Estadual do Centro-Oeste, campi de Irati e Guarapuava, Paraná. Contato: llpenkal@unicentro.br

\section{Resumo:}

Esta pesquisa (com apoio do CNPq, processo $n^{\circ} 443809 / 2014-3$ ), fundamentada nos pressupostos teórico-metodológicos da Sociolinguística Variacionista (LABOV, 1994, 2008), tem como objetivo investigar o processo de elevação da vogal média /o/, em posição postônica final, na fala em língua portuguesa de moradores da zona rural, descendentes de imigrantes eslavos (ucranianos e poloneses) da cidade de Irati, localizada na Região Centro-Sul do Paraná. Foram analisadas 24 entrevistas sociolinguísticas (com, no mínimo, 40 minutos de fala cada), estratificadas por sexo, duas faixas etárias (26 a 49 anos e 50 anos ou mais) e três níveis de escolaridade (fundamental I, fundamental II e ensino médio), pertencentes ao banco de dados do projeto VARLINFE (Variação Linguística de Fala Eslava). No total, foram elencadas e testadas sete variáveis linguísticas e quatro sociais. Os dados foram submetidos ao tratamento estatístico do Programa GoldVarb X e apontam um baixo índice de elevação da vogal estudada.

\section{Palavras-chave:}

Elevação vocálica. Etnia eslava. Projeto VARLINFE.

Signum: Estudos da Linguagem, Londrina, v. 21, n. 3, p. 367-385, dez. 2018 


\section{Elevação da Vogal Átona Final /O/ em Irati, Paraná}

Lucelene Teresinha Franceschini; Loremi Loregian-Penkal

\section{INTRODUÇÃo}

O sistema vocálico do português do Brasil foi descrito por Câmara Jr. (2004) a partir da incidência ou não do acento. Segundo sua proposta, o português compreende vogais tônicas, vogais pretônicas, vogais postônicas não finais e vogais postônicas finais. Em sílaba tônica, por sua função distintiva, preserva-se um sistema de sete vogais /i u e o $\rho \varepsilon$ a/, conforme mostram os seguintes exemplos de Bisol (2010, p. 42): s[i]co, $\mathrm{s}[\mathrm{e}] \mathrm{co}, \mathrm{s}[\varepsilon] \mathrm{co}, \mathrm{s}[\mathrm{a}] \mathrm{co}, \mathrm{s}[\mathrm{o}] \mathrm{co}, \mathrm{s}[\mathrm{o}] \operatorname{co}$ e s[u]co.

Nas sílabas átonas, esse sistema vocálico de sete vogais fica reduzido, pois certas oposições são suprimidas, o que foi interpretado por Câmara Jr. (2004) como neutralização. Em posição pretônica, ocorre a perda da distinção entre as vogais médias e/ع e o/っ, resultando num sistema de cinco vogais: /i u e o a/. Em relação às átonas não finais, o autor explica que o processo de neutralização ocorreu entre as vogais médias /o/ e /u/, mas não entre /e/ e /i/, resultando num sistema vocálico átono não final de quatro vogais: /i u e a/. Para ilustrar a neutralização entre /o / e /u/, Bisol (2003, p. 273) cita como exemplos as palavras fósf[u]ro e abób[u]ra.

As vogais nas sílabas átonas finais, de acordo com Câmara Jr. (2004), ficam reduzidas a três, ocorrendo a neutralização entre as médias e as altas. Nesse caso, o traço que distingue /e/ e /i/ de um lado, e /o/ e /u/ de outro, em termos de média versus alta, é neutralizado, como em: tard $[i]$ e bol[u]. O quadro postônico final fica, então, representado apenas por três vogais: /i a u/.

No entanto, em nota de rodapé, Câmara Jr. (2004, p. 44) diz: "numa ou noutra área do Sul do Brasil não há a neutralização e, por exemplo, jure (de jurar) se opõe a júri (tribunal popular)". O autor reconhece, portanto, que a realização das vogais átonas finais no Sul do Brasil apresenta um quadro distinto, pois em algumas áreas a neutralização dessas vogais não ocorre, o que várias pesquisas, realizadas em décadas posteriores aos escritos de Câmara Jr., comprovaram.

Assim, pode-se dizer que tanto a vogal átona final /o/ quanto a vogal átona final /e/ apresentam tendências de elevação quase categórica na maioria das cidades brasileiras. No entanto, no português falado no Sul do Brasil, a elevação dessas vogais finais apresenta um quadro variável, podendo realizar-se tanto o sistema de três vogais /i, a, u/, quanto o de cinco /i, e, a, o, u/, conforme mostram estudos realizados nessa região.

Considerando essa variação no português falado, esta pesquisa tem como objetivo descrever a realização da vogal postônica final /o/ e os fatores linguísticos e sociais que 
condicionam a elevação dessa vogal na fala de vinte e quatro informantes, descendentes de poloneses e ucranianos, moradores da zona rural de Irati, Paraná. Citaremos, inicialmente, alguns estudos que analisaram a realização das vogais átonas finais no português do Brasil.

\section{As Vogais Átonas Finais no Sul do Brasil}

Dois estudos de Vieira $(2002,2009)$ apresentam análises a respeito da elevação das vogais átonas finais no Sul do Brasil. Em Vieira (2002), a autora analisou as vogais /e/ e /o/ finais e não finais de oito informantes de cada uma das cidades do banco de dados do Projeto VARSUL (Variação Linguística Urbana na Região Sul do Brasil). Seus resultados mostraram a preservação das vogais átonas finais na fala dos habitantes de algumas das cidades analisadas, com destaque para Curitiba, Chapecó, Flores da Cunha e Irati.

Em Vieira (2009), a autora analisou o comportamento das vogais médias /e/ e /o/ na fala de 48 informantes, 16 informantes de cada uma das capitais da Região Sul - Curitiba, Florianópolis e Porto Alegre. Em relação às postônicas finais com /o/, a autora verificou que os percentuais de aplicação da regra de elevação de /o/ postônico final são bastante altos nas três capitais, podendo ser considerados praticamente categóricos para Porto Alegre (97\%) e Florianópolis (95\%). Curitiba também apresentou um importante percentual de elevação (81\%).

No Rio Grande do Sul, Machry da Silva (2009) analisou a elevação das vogais médias postônicas em dados de fala de 14 informantes de Rincão Vermelho, uma localidade rural, situada na fronteira com a Argentina. Seus resultados mostram que o alçamento das vogais /e/ e /o/ em posição final ocorre variavelmente, com maior probabilidade de aplicação para a vogal média /o/. Os falantes da comunidade em estudo elevam essa vogal quase na mesma medida em que a preservam, apresentando uma leve tendência para o alçamento $(55 \%)$.

Também no Rio Grande do Sul, Mileski (2013) analisou a elevação das vogais médias átonas finais no português falado por 24 informantes, descendentes de imigrantes poloneses residentes na comunidade rural de Vista Alegre do Prata. Seus resultados apontaram um percentual de elevação significativamente mais baixo que o encontrado em outras localidades, com 5,6\% de elevação da vogal átona final /o/ e 2,5\% de elevação da vogal final /e/.

Os trabalhos citados, dentre outros, apresentam resultados bastante significativos sobre a realização variável da vogal átona final /o/ no Sul do Brasil. Na medida do possível, procuraremos comparar nossos resultados aos obtidos nesses estudos. No entanto, destaca-se que cada um desses trabalhos organizou distintamente as variáveis independentes e, nestas, os fatores, especialmente no que se refere às variáveis contexto precedente e contexto seguinte, fato que, em alguns casos, dificulta generalizações. 


\section{A Comunidade de Irati, Paraná}

Por volta de 1830, Pacífico de Souza Borges e Cipriano Francisco Ferraz, dois aventureiros, desbravaram a região onde hoje se localiza a cidade de Irati, e ao encontrarem uma enorme abelheira denominaram o lugar de Iraty, vocábulo de origem tupi formado por ira e ty que significam, respectivamente, "mel" e "rio" na língua indígena. Posteriormente, na região ficava a vila de Covalzinho e, em 1890, quando a estrada de ferro São Paulo - Rio Grande do Sul cortou a vila, foi instalada uma estação ferroviária que recebeu o nome de Iraty. Em 1907, a agora vila de Iraty foi elevada a distrito. ${ }^{1}$

De acordo com o histórico do IBGE (2017b),

até a época da declaração da guerra, no ano de 1865, era pleno sertão o território do atual município de Irati. Logo após a declaração da guerra, foi decretado o recrutamento da Guarda Nacional e das tropas de primeira linha. Diversas famílias, temerosas de serem atingidas pelo recrutamento, se refugiaram no sertão, dando origem à formação de pequeno povoado, que recebeu a denominação de Covàzinho ou Covalzinho. Mais tarde, em 1899, o coronel Francisco de Paula Pires e o Sr. Emílio Batista Gomes adquiriram vasta área de terras na localidade, fixaram-se em plena mata virgem para lançarem os fundamentos da futura cidade de Irati. Naquela época, a região se constituía área territorial do município de Santo Antônio de Imbituva, mais tarde simplesmente lmbituva. O primeiro projeto de sua localização era o da Vila de São João, conhecida presentemente pela denominação de Irati Velho, e situada em lugar alto, plano, pitoresco e aprazível, com a aspiração de ser, futuramente, servida pelos trilhos da Estrada de Ferro São Paulo - Rio Grande, o que, entretanto, não aconteceu, uma vez que, ao ser construída, aquela ferrovia foi desviada da vila marginando as colinas para atingir o Covalzinho, sendo então inaugurada a Estação Ferroviária e Telegráfica, com a denominação de Estação de Irati.

De acordo com a Apresentação do Atlas Linguístico do Paraná (AGUILERA, 1996), o povoamento da cidade recebeu imigrantes de várias etnias e em diferentes épocas: em 1839 chegaram os bandeirantes paulistas; novas levas de colonizadores procedentes do sul paranaense chegaram por volta de 1864; em 1908 foi a vez dos imigrantes ucranianos, poloneses e holandeses atraídos ao país pelo movimento colonizador dirigido pelo Governo Federal. Atualmente, segundo o Censo 2010 do IBGE (2017a), a população total do município é de 60.070 mil habitantes, sendo que $79,94 \%$ - ou 44.932 - é considerada urbana, e 20,06\% - ou 11.275 - é considerada rural. A cidade fica a $150 \mathrm{Km}$ de Curitiba e possui uma área territorial total de $999,5 \mathrm{Km}^{2}$.

\footnotetext{
${ }^{1}$ Informações históricas de Irati disponíveis em <www.irati.pr.gov.br>. Acesso em: 08 out. 2012.
} 


\section{Metodologia}

Este estudo está apoiado, especialmente, nos pressupostos da Teoria da Variação e Mudança Linguística, delineada por Weinreich, Labov e Herzog (2006) e Labov (2008). Foram levantados, por meio da análise de oitiva, os dados de elevação e de não elevação da vogal média-alta posterior /o/ em posição átona final de 24 entrevistas sociolinguísticas (com no mínimo 40 minutos de fala cada) realizadas com descendentes de poloneses e ucranianos, moradores da zona rural de Irati, cidade localizada na região Centro-Sul do Paraná.

Os 24 informantes da amostra foram estratificados em duas faixas etárias, sexo e três níveis de escolaridade. As entrevistas fazem parte do banco de dados Variação Linguística de Fala Eslava - VARLINFE, que contém amostras de fala de sete cidades do centro-sul paranaense, quais sejam: Mallet, Irati, Prudentópolis, Rio Azul, Rebouças, Ivaí e Cruz Machado. Para a análise estatística dos dados, utilizamos o programa GoldVarbX.

\section{Banco De Dados VARLINFE}

O Banco de Dados VARLINFE ${ }^{2}$ foi montado por pesquisadores da área de Sociolinguística da Unicentro, campus de Irati, e surge, em um cenário de forte imigração eslava, como uma maneira importante de registrar o patrimônio imaterial/linguístico de descendentes de eslavos de sete cidades da região sudeste do interior do Paraná: i) Irati; ii) Rebouças; iii) Rio Azul; iv) Ivaí; v) Mallet; vi) Prudentópolis; e vii) Cruz Machado.

Para a montagem do VARLINFE foi adotada a mesma metodologia do Projeto Variação Linguística Urbana na Região Sul - VARSUL, mas com um diferencial importante: optou-se por registrar a fala de descendentes eslavos da zona rural das localidades selecionadas. O perfil dos informantes contemplou os seguintes critérios, consagrados em pesquisas sociolinguísticas: 1) falantes descendentes de eslavos (ou seja, o informante deveria ser descendente de ucraniano ou polonês, de pai ou de mãe ou de ambos e ter nascido na comunidade e/ou ter se mudado para lá, no máximo, aos 2 anos de idade); 2) não ter viajado para outras localidades (por exemplo, o informante não poderia ter sido caminhoneiro ou vendedor); 3) morar na zona rural de um dos sete municípios incluídos na amostra.

As características sociais dos informantes do VARLINFE são estas: sexo (12 informantes do sexo masculino e 12 do feminino); idade (12 informantes de 25-49 e 12 acima de 50 anos); e escolaridade (8 informantes de 1 a 4 anos de escola; 8 de 5 a 8 anos de escola; e 8 informantes de 9 anos de escola ou mais).

Além desses critérios, foram levados em consideração, também, para a montagem do Banco: (i) elaboração e preenchimento de ficha social, que detalha o perfil social do

\footnotetext{
${ }^{2}$ Maiores detalhes podem ser obtidos em Loregian-Penkal et al. (2013).
} 
entrevistado; (ii) elaboração do roteiro de perguntas, que prioriza a coleta de narrativas de experiência pessoal; (iii) obtenção de anuência do entrevistado via assinatura do Termo de Consentimento Livre e Esclarecido - TCLE.

\section{VARIÁVEIS ANALISADAS}

Nesta pesquisa foram levantadas todas as ocorrências da vogal média posterior /o/ em contexto silábico postônico final de 24 entrevistas sociolinguísticas de Irati. Os entrevistados eram moradores da zona rural do município e todos eram descendentes de poloneses/ucranianos com forte vivência na cultura dessas etnias.

Como variável dependente postulamos a elevação de /o/ átono final versus a não elevação de /o/ final. Nas rodadas, definimos como valor de aplicação da regra a elevação. As variáveis sociais analisadas foram quatro: as já citadas faixa etária, escolaridade e sexo, além de etnia (ucraniana, polonesa e híbrida). As variáveis linguísticas independentes consideradas na análise e seus respectivos exemplos de ocorrência seguem especificados a seguir.

1. Tipo de consoante/vogal em contexto precedente

Esta variável foi considerada para verificar se o tipo de consoante - ou vogal - que antecede a vogal /o/ interfere em sua produção, elevada para/u/ ou não. Os fatores controlados foram:

1.1 Oclusiva [p, b, t, d, k, g]: "Os antigo eram rígido na religião"3 (IRT 20 M1COLP)4

1.2 Fricativa [f, v, s, z, $\left.\int, 3, \mathrm{x}\right)$ ]: "Brincava com balanço de cipó," (IRT 17M1GINH)

1.3 Nasal [m, n, j]: "E assim que nós conseguimo se formá”( (IRT 20 M1COLP)

1.4 Lateral [1, K]: "Sai na casa dos filho, dos parente" (IRT 23M2PRIU)

1.5 Rótico [r]: "Mas não sei quanto que tinha que tê de dinheru e ai desisti" (IRT 06 F1COLH)

1.6 Vogal [1]: "De naviu sessenta dia e ssesenta noite de naviu né” (IRT 06 F1COLH)

2. Ponto de articulação do som consonantal em contexto precedente

Com o controle desta variável pretendeu-se analisar a influência que o ponto de articulação da consoante, em contexto precedente, exerce na realização da vogal média postônica /o/. Os seguintes fatores foram controlados:

\footnotetext{
${ }^{3}$ Nos exemplos dos dados de fala, optamos por transcrição ortográfica simples.

${ }^{4}$ Notação que identifica os informantes e as variáveis sociais: Ma - Mallet; número que identifica o informante; M ou F - sexo; 1 ou 2: 1 faixa etária, até 50 anos, e 2 faixa etária, mais de 50 anos; PRI (Primário, 1 a 4 anos de escola), GIN (Ginásio, 5 a 8 anos de escola), COL (Colegial, 9 a 11 anos de escola) - grau de escolaridade; P (Polonesa), U (Ucraniana), H (Híbrida: ucraniano e polonês) etnia.
} 
2.1 Bilabial [p, b, m]: "Eu com fumu nunca trabalhei” (IRT 14 F2COLH)

2.2 Labiodental [f, v]: "Lá tinha muito favu de mel tamem" (IRT 11 F2GINH)

2.3 Alveolar [t, d, n, s, z, r, l]: "dai ficô trabalhando e estudando."(IRT 17M1GINH)

2.4 Pós-alveolar [t $\left.\int, \mathrm{d} 3, \int, 3\right]$ : "Acho que era trigo, fejão" (IRT 23M2PRIU)

2.5 Palatal [n,, ]: "Eles fazium esses bolinhu né?" (IRT 11 F2GINH)

2.6 Velar [k, g, x]: “Tinha castigo esses tempo" (IRT 15M1PRIH)

3. Tipo de som em contexto posterior

O tipo de som em contexto posterior foi controlado para verificar se o contexto seguinte à variante em análise pode interferir na preservação de /o/ ou em sua elevação para /u/. Foram considerados os fatores:

Se consoante:

3.1 Oclusiva [p, b, t, d, k, g]: "eu sô o mais novo da turma" (IRT 25M2GINU)

3.2 Fricativa $\left[\mathrm{f}, \mathrm{v}, \mathrm{s}, \mathrm{z}, \int, 3, \mathrm{x}\right]$ :"Mais sofrid $u$ só que como a gente era criança" (IRT 02 F1PRIU)

3.3 Nasal [m, n, n]: "Já tá passando do ponto minhas muda"(IRT 15M1PRIH)

3.4 Lateral [1, K]: "Eu não tenho lembrança" (IRT 23M2PRIU)

3.5 Rótico [r]: "É tudo misturado, é quatro religião ali" (IRT 24M2GINP)

3.6 Africada [t $\int$, d3]: "É a única coisa que tá dando dzinhero né” (IRT 18M1GINU)

Se vogal:

3.7 Anterior alta [i]: "Tem quatro igreja” (IRT 23M2PRIU)

3.8 Anterior média [e, ع]: "O fumo eles mesmo produziam” (IRT 26M2COLP)

3.9 Posterior alta [u]: "Eu tenho uns pé de couve flor" (IRT 16M1PRIH)

3.10 Posterior média [o, o]: "Era fundo os riu" (IRT 22M2PRIP)

3.11 Baixa [a]: "e deu aquele fri $u$ aquela veiz" (IRT 15M1PRIH)

3.12 Pausa: "Nós plantamo fumo." (IRT 18M1GINU)

4. Ponto de articulação do som consonantal seguinte

Esta variável foi considerada para verificar se o ponto de articulação da consoante seguinte à vogal /o/ interfere em sua produção, elevada para /u/ ou não. Os seguintes fatores foram controlados:

4.1 Bilabial [p, b, m]: "A gente respondia em brasilero pra ele" (IRT 27M2COLP)

4.2 Labiodental [f, v]: "Pegum o alto falante e ficum cantandu lá né?" (IRT 08 F1COLU)

4.3 Alveolar [t, d, n, s, z, r, 1]: "Era sofrido também" (IRT 24M2GINP)

4.4 Pós-alveolar $\left[\int, 3, \mathrm{t} \int, \mathrm{d} 3\right]$ : "Tanto ucraíno dziminuíu como os polaco" (IRT 24M2GINP)

4.5 Velar [k, g, x]: “É claro que sempre muda” (IRT 16M1PRIH) 
5. Sonoridade do segmento precedente

Esta variável foi considerada para verificar se a sonoridade (vozeada ou desvozeada) da consoante que precede a vogal /o/ influencia na sua produção, elevada para /u/ ou não. Foram considerados os fatores:

5.1 Vozeado: "Daí é mais divertidu né? (IRT 06 F1COLH)

5.2 Desvozeado: "Aquele charuto, pirogui, já dexavam pronto né” (IRT 17M1GINH)

6. Tipo de sílaba

Com o controle desta variável buscou-se verificar se o tipo de sílaba (pesada/CVC ou leve/CV) influencia no comportamento da vogal média /o/ em posição postônica, favorecendo ou inibindo o alçamento. Para tanto, foram considerados os seguintes fatores:

6.1 Com coda: "Diferença de um ano e meio, dois anus assim" (IRT 25M2GINU) 6.2 Sem coda: "A mãe entende um poco de ucraniano né" (IRT 16M1PRIH)

7. Presença/ausência de vogal alta na palavra

Esta variável foi considerada para verificar se a presença de uma vogal alta - /i/ e /u/ - na palavra influencia na preservação de /o/ átono final ou em seu alçamento para $/ \mathrm{u} /$. Os seguintes fatores foram considerados:

7.1 Presença de vogal alta: "Tem pinherinhu eles enfeitum o pinherinhu." (IRT 08 F1COLU)

7.2 Ausência de vogal alta: "Faz tempo, logo que casei” (IRT 25M2GINU)

Estas sete variáveis linguísticas, somadas às variáveis sociais sexo, escolaridade, faixa etária e etnia, foram devidamente codificadas para que pudéssemos rodar o programa GoldVarbX, cujos resultados encontram-se na seção a seguir.

\section{Resultados da Análise da Vogal Átona Final /o/ em Irati, Paraná}

$\mathrm{Na}$ análise das 24 entrevistas de Irati, em um total de 5.573 ocorrências, obtivemos 9,3\% (517 dados) de elevação e 90,7\% (5.056 ocorrências) de não elevação, ou seja, uma percentagem bastante elevada de não elevação da vogal átona final / o/. Verificamos, portanto, que em somente $9,3 \%$ das ocorrências os falantes realizaram a elevação da vogal átona final /o/ para /u/, o que confirma a baixa aplicação da regra de elevação no Paraná. A Figura 1 ilustra a realização dessa vogal final nos dados de Irati: 


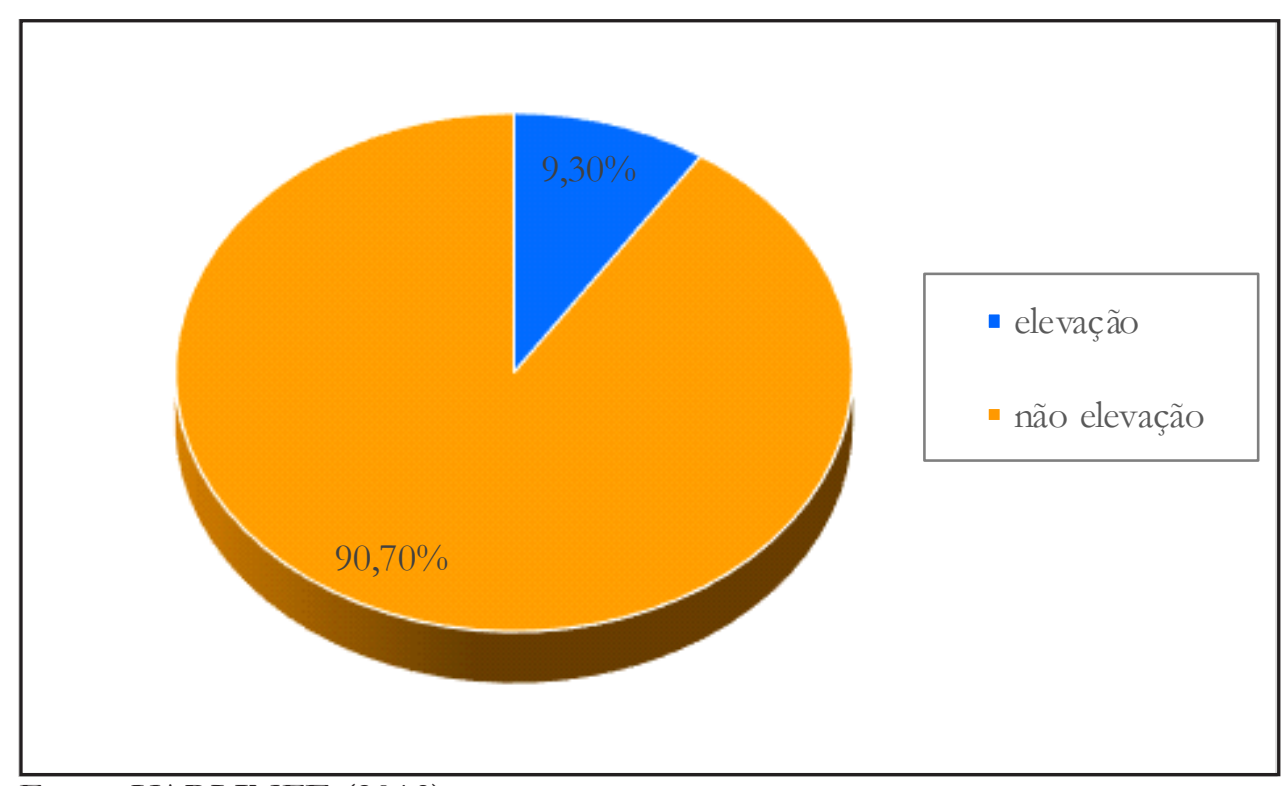

Fonte: VARLINFE (2013).

Figura 1 - Elevação da vogal átona final /o/

Constatamos também que esse percentual de elevação em Irati (9,3\%) é bastante reduzido se comparado aos resultados obtidos por Vieira (2009) nas capitais da Região Sul (Curitiba: 81\%; Florianópolis: 95\%; Porto Alegre: 97\%) e por Macrhy da Silva (2009) em Rincão Vermelho-RS (55\%), com percentuais de aplicação da regra de elevação de /o/ muito mais elevados. Já o trabalho de Mileski (2013), em Vista Alegre do Prata-RS, uma comunidade de descendentes de imigrantes poloneses, apresentou um resultado semelhante ao nosso, com somente 5,6\% de elevação da vogal /o/.

Destaca-se, ainda, que na rodada geral dos dados de Irati, o programa estatístico apresentou um input de somente 0,032 para a elevação de /o/ átono final, resultado que confirma o baixo percentual já verificado nos dados.

Em relação às variáveis linguísticas e sociais, o programa GoldVarbX selecionou, por ordem de significância, as seguintes variáveis: 1. tipo de sílaba; 2. sexo; 3. tipo de consoante/vogal em contexto fonológico precedente; 4. etnia; 5. ponto de articulação da consoante em contexto fonológico precedente; 6. presença /ausência de vogal alta; 7. sonoridade do segmento precedente; 8. ponto de articulação da consoante seguinte; 9. escolaridade; 10. contexto fonológico seguinte. Somente a faixa etária não foi selecionada pelo programa estatístico. Apresentamos, a seguir, os resultados das variáveis linguísticas selecionadas e, na sequência, os resultados das variáveis sociais.

\section{Variáveis linguísticas}

A variável selecionada em primeira posição, portanto como a mais relevante para a elevação da vogal estudada, foi o tipo de sílaba (com coda ou pesada e sem coda ou leve). Os resultados dessa variável são apresentados no Quadro 1: 
Quadro 1 - Tipo de sílaba (elevação)

\begin{tabular}{|c|c|c|c|}
\hline Fatores & Aplicação/Total & Frequência & P.R. \\
\hline Com coda & $227 / 530$ & 42,8 & 0,95 \\
\hline Sem coda & $290 / 5043$ & 5,8 & 0,42 \\
\hline $\begin{array}{c}\text { Total } \\
\text { Input: } 0,032\end{array}$ & $517 / 5573$ & 9,3 & \\
\hline
\end{tabular}

Fonte: VARLINFE (2013).

Conforme observamos no Quadro 1, as sílabas com coda (muitus, novecentus) são altamente favorecedoras da elevação $(0,95)$; já as sílabas sem coda (casamento, fumo) desfavorecem a elevação $(0,42)$, apresentando um peso relativo de 0,58 para a não elevação da vogal átona final /o/. Destacamos que a grande maioria dos dados de elevação apresentaram a coda /s/, o que nos faz pensar que tanto pode ser a coda como a consoante /s/ o fator mais favorável à elevação.

Portanto, em relação às sílabas com coda, o resultado de nossos dados $(0,95$ para a elevação) corrobora os obtidos em Machry da Silva (2009), Vieira (2009) e Mileski (2013), pois, em todos esses trabalhos, com $0,82,0,90$ e 0,84 respectivamente, as sílabas com coda /s/ favoreceram a elevação de /o/ para /u/.

Quanto às sílabas sem coda, nossos resultados $(0,42)$, assim como os de Mileski $(0,38)$, mostram essas sílabas como favorecedoras da não elevação do /o/ átono final. Já nos demais trabalhos citados, com resultados bastante semelhantes entre si, as sílabas sem coda apresentam valores próximos ao ponto neutro, o que indica, como destaca Vieira (2002), que a ausência de coda parece não influenciar na preservação de /o/ ou em sua elevação para $/ \mathrm{u} /$.

Verificamos, assim, que o resultado da variável tipo de sílaba na amostra de Irati confirma o obtido em análises precedentes, principalmente no que se refere ao fator sílabas com coda, favorecedor à elevação da vogal final /o/.

Os resultados das variáveis tipo de consoante (ou vogal) em contexto fonológico precedente, ponto de articulação da consoante precedente e sonoridade (selecionadas em $2^{\mathrm{a}}, 5^{\mathrm{a}} \mathrm{e} 7^{\mathrm{a}}$ posição, respectivamente), que se referem ao segmento precedente à vogal analisada, são apresentados conjuntamente no Quadro 2. 
Quadro 2 - Consoante/vogal precedente

\begin{tabular}{|l|c|c|c|}
\hline \multicolumn{1}{|c|}{ Fatores } & Aplicação/Total & Frequência & P.R. \\
\hline Tipo de consoante/vogal & & & \\
Vogal $-i$ & $52 / 257$ & 20,2 & 0,83 \\
Nasal & $138 / 1186$ & 11,6 & 0,57 \\
Oclusiva & $188 / 2739$ & 6,9 & 0,52 \\
Lateral & $58 / 304$ & 19,1 & 0,47 \\
Rótico & $42 / 572$ & 7,3 & 0,38 \\
Fricativa & $39 / 515$ & 7,6 & 0,23 \\
\hline Ponto de articulação & & & 0,83 \\
Labiodental & $41 / 152$ & 27 & 0,64 \\
Bilabial & $69 / 512$ & 13,5 & 0,49 \\
Palatal & $32 / 465$ & 6,9 & 0,47 \\
Alveolar & $309 / 3595$ & 8,6 & 0,45 \\
Velar & $22 / 496$ & 4,4 & 0,56 \\
\hline Sonoridade & & 11,7 & 0,36 \\
Vozeado & $466 / 3971$ & 3,2 & \\
Desvozeado & $51 / 1602$ & &
\end{tabular}

Fonte: VARLINFE (2013).

A variável tipo de consoante/vogal precedente apresentou como fatores favoráveis à elevação a vogal $-\mathrm{i}(0,83)$ e as nasais $(0,57)$. As oclusivas e as laterais apresentaram um peso relativo próximo ao ponto neutro $(0,52$ e 0,47 , respectivamente); já o rótico $(0,38)$ e, especialmente, as fricativas $(0,23)$ desfavoreceram a elevação de /o/ para /u/.

Essa variável, aliada ao ponto de articulação dos sons e rotulada como contexto precedente em outros trabalhos, foi selecionada em todas as pesquisas citadas. No entanto, as diferenças na constituição dos fatores das variáveis dificultam comparações entre os resultados ou generalizações. Em nossa análise, separamos o contexto precedente pelo modo de articulação dos sons (oclusiva, fricativa, rótico, lateral etc.) e ponto de articulação (alveolar, bilabial, palatal etc.); já os demais estudos analisaram as consoantes como coronais [+anterior] e [-anterior], dorsais e labiais, amalgamando ou isolando os diversos fatores.

Nos dados de Irati, os resultados da variável ponto de articulação da consoante em contexto fonológico precedente mostram que a elevação é favorecida principalmente pelas consoantes labiodentais $(0,83)$, seguidas das bilabiais $(0,64)$; já as demais consoantes (palatais, alveolares e velares) apresentam um resultado próximo ao ponto neutro.

$\mathrm{Na}$ análise de Machry da Silva (2009), as consoantes labiais (adubo, primo) apresentaram peso relativo de 0,45 , figurando como neutras, com leve tendência à preservação, as coronais [+ant] (brinquedo, curso), com peso relativo de 0,55, apresentaram um leve favorecimento ao 
processo de elevação, Com menor peso relativo, 0,38 , encontram-se as coronais [-ant] amalgamadas com as dorsais (tacho, plastico), mostrando ser o contexto que mais inibe o alçamento da vogal /o/ final. Em Mileski (2013), as labiais $(0,42)$ também se mostraram pouco favorecedoras da elevação, além da vogal alta $(0,42)$ e das coronais [+ant] $(0,33)$, pois todas apresentaram peso relativo abaixo do ponto neutro. Os resultados dessa autora indicaram, ainda, que consoantes coronais [-ant] favorecem o alçamento da vogal média átona final $/ \mathrm{o} /(0,76)$ e as consoantes dorsais e os segmentos $[\mathrm{s}, \mathrm{z}]$ apresentam comportamento neutro (0,52 e 0,51 respectivamente).

Ao contrário, nos dados de Vieira (2010), as consoantes labiais $(0,60)$ e as vogais $(0,64)$, assim como as fricativas $(0,60)$, favoreceram a elevação da vogal final /o/; já as oclusivas, as líquidas e as dorsais apresentaram, para a preservação da vogal /o/, pesos relativos de $0,55,0,54$ e 0,53 , respectivamente.

Considerando a distinta organização dos fatores nas pesquisas citadas, ressaltamos a dificuldade de comparações entre os resultados de nossa amostra e aqueles apresentados nessas análises precedentes. Apesar disso, podemos dizer que os resultados de Irati aproximam-se parcialmente aos obtidos por Vieira (2010), pois as consoantes labiodentais e bilabiais (labiais) e as vogais, em ambos os trabalhos, favoreceram a elevação da vogal final /o/. Já em Machry da Silva (2009) e em Mileski (2013), as labiais desfavoreceram a elevação de $/ \mathrm{o} /$.

A variável sonoridade, que foi considerada para verificar se segmentos vozeados ou desvozeados que precedem a vogal /o/ influenciam na sua produção, elevada para / $\mathrm{u} / \mathrm{ou}$ não, também foi considerada significativa em nossa análise. Verificamos que a elevação predomina com os segmentos vozeados $(0,56)$; já os desvozeados, com peso relativo de 0,36 para a elevação, favoreceram a preservação da vogal final /o/.

A presença ou ausência de vogal alta na palavra foi a sexta variável selecionada pelo programa estatístico. Os resultados dessa variável são apresentados no Quadro 3:

Quadro 3 - Presença/ausência de vogal alta na palavra

\begin{tabular}{|l|c|c|c|}
\hline Fatores & Aplicação/Total & Frequência & P.R. \\
\hline Presença & $344 / 2808$ & 12,3 & 0,60 \\
\hline Ausência & $173 / 2765$ & 6,3 & 0,39 \\
\hline Total & $517 / 5573$ & 9,3 & \\
\hline
\end{tabular}

Fonte: VARLINFE (2013).

Os resultados mostram que a presença de vogal alta na palavra favorece a elevação da vogal /o/ para /u/, com um peso relativo de 0,60 ; já a ausência de vogal alta desfavorece a elevação de /o/ (0,39). Segundo Vieira (2002), esse comportamento está associado a um processo de assimilação progressiva, pelo qual a vogal média postônica assimila o traço de altura da vogal da sílaba precedente. 
As análises de Machry da Silva (2009) e Vieira (2009) apontaram a presença de vogal alta na palavra como um dos fatores mais favorecedores para a elevação de /o/ átono final $(0,82$ e 0,90 , respectivamente); já a ausência de vogal alta inibiu a elevação de /o/, com pesos de 0,28 e 0,30 . No estudo de Mileski (2013) também a presença de vogal alta favoreceu a elevação de /o/ átono final $(0,57)$, e sua ausência desfavoreceu a elevação $(0,42)$.

Nossos resultados para a variável presença/ausência de vogal alta na palavra, semelhantes aos de Mileski (2013), embora não tão polarizados quanto os obtidos nos outros trabalhos citados, confirmam a hipótese de que a presença de vogal alta na palavra condiciona a elevação da vogal átona final /o/ para / u/, conforme já demonstraram Machry da Silva (2009) e Vieira (2009).

Em relação à consoante seguinte, as variáveis ponto de articulação da consoante seguinte ( $8^{a}$ posição) e tipo de consoante/vogal (10 posição) foram selecionadas. Os resultados dessas variáveis figuram no Quadro 4:

Quadro 4 - Ponto de articulação e contexto seguinte

\begin{tabular}{|l|c|c|c|}
\hline \multicolumn{1}{|c|}{ Fatores } & Aplicação/Total & Frequência & P.R. \\
\hline Ponto de articulação & & & \\
Pós-alveolar & $30 / 125$ & 24,0 & 0,73 \\
Alveolar & $158 / 1799$ & 8,8 & 0,53 \\
Bilabial & $27 / 435$ & 6,2 & 0,47 \\
Velar & $26 / 476$ & 5.5 & 0,42 \\
Labiodental & $5 / 127$ & 3,9 & 0,23 \\
\hline Contexto seguinte & & & \\
Fricativa & $51 / 335$ & 15,2 & 0,66 \\
Posterior média (o, ó) & $41 / 194$ & 21,1 & 0,63 \\
Anterior média (e, é) & $92 / 565$ & 16,3 & 0,54 \\
Baixa (a) & $67 / 582$ & 11,5 & 0,54 \\
Oclusiva & $119 / 1501$ & 7,9 & 0,52 \\
Lateral & $5 / 102$ & 4,9 & 0,49 \\
Pausa & $67 / 1126$ & 6,0 & 0,45 \\
Posterior alta (u) & $5 / 59$ & 8,5 & 0,44 \\
Nasal & $69 / 981$ & 7,0 & 0,44 \\
Anterior alta (i) & $1 / 73$ & 1,4 & 0,13 \\
\hline
\end{tabular}

Fonte: VARLINFE (2013)

A análise do contexto seguinte mostrou que o ponto de articulação da consoante seguinte também pode interferir na aplicação da elevação ou da não elevação da vogal postônica /o/. Conforme podemos observar no Quadro 4, os resultados apontaram como fatores favoráveis à elevação as consoantes pós-alveolares $(0,73)$; já as alveolares $(0,53)$, assim como as bilabiais $(0,47)$, apresentaram um resultado próximo ao ponto neutro, e as consoantes velares $(0,42)$ e, principalmente, as labiodentais $(0,23)$ desfavoreceram a elevação.

Em relação ao tipo de consoante/vogal seguinte, verificamos que as consoantes fricativas $(0,66)$, assim como a vogal posterior média $(0,63)$, favorecem a elevação; já a vogal 
anterior alta desfavorece a elevação $(0,13)$. As demais consoantes e vogais apresentam resultados próximos ao ponto neutro, ora com um leve favorecimento da elevação (vogal anterior média, baixa e consoante oclusiva), ora com pesos um pouco abaixo do ponto neutro para a elevação (consoantes laterais, nasais e vogal posterior alta). As africadas (38 dados) e o rótico (15 dados) apresentaram nocaute, pois 100\% das ocorrências foram de não elevação. Em relação às vogais, os resultados não confirmaram o esperado, pois as vogais altas em contexto seguinte, que acreditávamos favorecer a elevação, a desfavoreceram.

Outras pesquisas também analisaram o papel do contexto seguinte na realização do /o/ átono final, embora tenham determinado esse contexto em função de traços fonológicos distintos, conforme já mencionamos em nossa análise do contexto precedente. Em relação à análise das vogais, verificamos que Machry da Silva (2009) e Mileski (2013) analisaram conjuntamente todas as vogais; já em nossa pesquisa, classificamos as vogais de acordo com a anterioridade/posterioridade e altura (anterior/posterior e alta/média/baixa).

Em Rincão Vermelho-RS, Machry da Silva (2009) verificou que o contexto seguinte vogal, com peso relativo de 0,57, favoreceu o alçamento de /o/ em posição final. As consoantes coronais [+ant] e a pausa apresentaram peso relativo de 0,50 , figurando como neutras. A autora também observou um comportamento neutro para as consoantes labiais, com peso relativo de 0,48. Já as consoantes coronais [-ant] amalgamadas com dorsais, com peso relativo de 0,43 , demonstraram leve tendência à preservação da vogal.

Em Vista Alegre do Prata-RS, Mileski (2013) verificou que as consoantes dorsais $(0,61)$, as vogais $(0,60)$ e a pausa $(0,56)$ favoreceram a elevação da vogal átona final /o/, as consoantes labiais mostraram um comportamento neutro $(0,50)$ e as coronais [+ant] e coronais [-ant], com peso relativo abaixo do ponto neutro $(0,43$ e 0,28 , respectivamente), desfavorecem a elevação.

Observamos, portanto, que, em Machry da Silva (2009) e Mileski (2013), as vogais (analisadas conjuntamente) favorecem a elevação. Também em nosso estudo, as vogais médias e a baixa se mostraram favorecedoras da elevação; já as vogais altas, ao contrário do esperado, favoreceram a preservação de /o/. Em relação às consoantes, observamos que as pesquisas apresentam resultados bastante diferenciados.

\section{Variáveis sociais}

A seguir, apresentamos os resultados das variáveis sociais sexo, etnia e escolaridade, selecionadas em $2^{\mathrm{a}}, 4^{\mathrm{a}}$ e $9^{\mathrm{a}}$ posições, respectivamente. A variável sexo, selecionada em $2^{\mathrm{a}}$ posição, apresentou resultados bastante significativos em nossos dados, conforme mostra o Quadro 5: 
Quadro 5 - Sexo

\begin{tabular}{|l|c|c|c|}
\hline \multicolumn{1}{|c|}{ Fatores } & Aplicação/Total & Frequência & P.R. \\
\hline Feminino & $375 / 2480$ & 15,1 & 0,77 \\
\hline Masculino & $142 / 3093$ & 4,6 & 0,27 \\
\hline Total & $517 / 5573$ & 9,3 & \\
\hline
\end{tabular}

Fonte: VARLINFE (2013).

Conforme podemos observar no Quadro 5, o sexo feminino favorece a elevação da vogal átona final /o/ (0,77), enquanto o sexo masculino, com somente 0,27 para a elevação, favorece a preservação da vogal final /o/. Esses resultados parecem demostrar que as mulheres, geralmente mais sensíveis às normas de maior prestígio ou às inovações, se mostram mais favoráveis à elevação da vogal postônica final /o/.

Diversos estudos já demonstraram a influência do fator sexo na escolha das formas linguísticas utilizadas por homens e mulheres. Labov (2008) destaca que, em situação de variação estável, as mulheres têm demonstrado preferência ao uso das formas de prestígio. No entanto, conforme esse autor, a tendência de liderança das mulheres às formas inovadoras não pode ser generalizada, visto que é preciso verificar o papel de outros fatores sociais que podem interferir nesse comportamento.

Machry da Silva (2009), em Rincão Vermelho-RS, verificou que os homens apresentaram um leve favorecimento $(0,54)$ para a elevação, e as mulheres uma leve tendência à preservação da vogal média /o/ final $(0,46)$. Para melhor entender o comportamento linguístico dos homens e das mulheres de sua amostra, a autora realizou um cruzamento entre as variáveis tipo de contato com os centros vizinhos e sexo. Esse cruzamento mostrou que homens e mulheres que possuem contato frequente com centros vizinhos tendem a elevar a vogal postônica final /o/. Segundo a autora, tais resultados confirmam que o tipo de contato com centros urbanos exerce influência no comportamento linguístico de homens e mulheres, mostrando-se mais evidente entre as mulheres.

Nos estudos de Vieira (2009) e Mileski (2013), a variável sexo não foi considerada significativa para a elevação ou não elevação da vogal átona final /o/.

Em relação à etnia, controlamos se o informante tinha descendência ucraniana, polonesa ou híbrida, por parte de pai, mãe ou cônjuge. Quando o informante apresentava descendência ucraniana e polonesa, este foi classificado como híbrido. Esta terceira classificação foi necessária porque temos vários informantes da amostra que se enquadram tanto como descendentes de ucranianos quanto de poloneses, "miscigenação" bastante comum na região pesquisada.

Os resultados da variável etnia, selecionada em $4^{a}$ posição pelo programa estatístico, são apresentados no Quadro 6: 
Quadro 6 - Etnia

\begin{tabular}{|l|c|c|c|}
\hline \multicolumn{1}{|c|}{ Fatores } & Aplicação/Total & Frequência & P.R. \\
\hline Poloneses & $176 / 1676$ & 10,5 & 0,70 \\
\hline Híbridos & $197 / 1844$ & 10,7 & 0,47 \\
\hline Ucranianos & $144 / 2053$ & 7,0 & 0,36 \\
\hline Total & $517 / 5573$ & 9,3 & \\
\hline
\end{tabular}

Fonte: VARLINFE (2013)

Os resultados mostram que a etnia que mais favorece a elevação de /o / átono final, em Irati, é a polonesa (0,70); os híbridos apresentam um resultado próximo ao ponto neutro $(0,47)$ e os ucranianos desfavorecem a elevação $(0,36)$, favorecendo a preservação da vogal final $/ \mathrm{o} /$.

Observamos que os resultados para a etnia polonesa e ucraniana em nossa análise da elevação da vogal /o/ são semelhantes aos obtidos por Loregian-Penkal e Costa (2016) na análise da vogal átona final /e/ na comunidade de Mallet-PR, também formada por descendentes de poloneses e ucranianos. Nessa comunidade, as autoras verificaram que os descendentes de poloneses favoreciam a elevação da vogal final e os ucranianos, ao contrário, favoreciam sua preservação.

Segundo as autoras, a manutenção da cultura de origem poderia estar influenciando na tendência à elevação ou não de /e/. Assim, a preservação das vogais finais por parte dos descendentes de ucranianos estaria relacionada ao maior contato com sua cultura de origem (atividades culturais e religiosas, uso da língua), enquanto a elevação das vogais átonas finais, ou seja, o maior uso da forma inovadora pelos descendentes de poloneses, estaria relacionada à menor manutenção da cultura de origem nesse grupo. Assim, acreditamos que, na zona rural de Irati, da mesma forma que em Mallet, a maior preservação do /o/ final pelos descendentes de ucranianos e sua elevação para / u/ na fala dos descendentes de poloneses esteja relacionada ao maior/menor contato desses grupos com sua cultura de origem.

A última variável social considerada significativa foi a escolaridade, selecionada em $9^{a}$ posição.

Quadro 7 - Escolaridade

\begin{tabular}{|l|c|c|c|}
\hline \multicolumn{1}{|c|}{ Fatores } & Aplicação/Total & Frequência & P.R. \\
\hline Ensino Médio & $241 / 1840$ & 13,1 & 0,58 \\
\hline Fundamental I & $174 / 1892$ & 9,2 & 0,50 \\
\hline Fundamental II & $102 / 1841$ & 5,5 & 0,43 \\
\hline Total & $517 / 5573$ & 9,3 & \\
\hline
\end{tabular}

Fonte: VARLINFE (2013). 
A análise dos resultados permite concluir que os informantes com ensino médio, com peso relativo de 0,58 , mostram-se mais favoráveis ao processo de elevação da postônica /o/ em posição final. Já os informantes com ensino fundamental I apresentam um resultado no ponto neutro $(0,50)$, e os com fundamental II tendem a preservar a vogal nessa posição $(0,43)$.

Machry da Silva (2009) e Mileski (2013) analisaram os seguintes níveis de escolaridade: ensino superior, ensino médio e fundamental. Nos resultados de Machry da Silva (2009), o ensino superior e o ensino médio (0,71 e 0,66 , respectivamente) favoreceram a elevação, e o ensino fundamental a desfavoreceu (0,24). Já nos dados de Mileski (2013), o ensino fundamental e o médio apresentaram um peso relativo um pouco acima do ponto neutro $(0,52)$ e o ensino superior apresentou somente 0,21 para a elevação. Assim, enquanto os resultados de Machry da Silva (2009) parecem confirmar a hipótese de que os informantes com maior grau de escolaridade apresentariam um comportamento mais favorável ao processo de alçamento das vogais médias postônicas, os resultados obtidos por Mileski (2013) contrariam tal hipótese.

Nos dados de Irati, apesar de não termos uma escala gradual decrescente nos pesos atribuídos segundo a escolaridade dos falantes, o que podemos inferir é que a elevação predomina no nível de maior escolaridade, o ensino médio. No entanto, considerando os resultados dos níveis fundamental I e fundamental II, temos poucas evidências para confirmar a hipótese de que os informantes com maior grau de escolaridade apresentam um comportamento mais favorável ao processo de alçamento da vogal final /o/. Esse resultado necessita, portanto, de maiores refinamentos, para se chegar a uma conclusão mais consistente.

\section{Considerações FinaIs}

A partir dos resultados obtidos em nosso estudo, constatamos um reduzido percentual de elevação da vogal átona final /o/ nos dados de Irati-PR (9,3\%), ou seja, obtivemos 90,7\% de não elevação dessa vogal. Observamos ainda que o percentual de elevação em Irati é próximo ao obtido por Mileski (2013) em Vista Alegre do Prata-RS, uma comunidade rural, também constituída por descendentes de eslavos.

Considerando as variáveis linguísticas, os resultados do tipo de sílaba e presença/ ausência de vogal alta na palavra apresentaram tendências semelhantes às obtidas nos demais trabalhos citados. Em nosso estudo, a elevação de /o/ para / / foi favorecida nas sílabas com coda $(0,95)$ e nas palavras com vogal alta $(0,60)$.

Em relação às demais variáveis linguísticas selecionadas (tipo de consoante/vogal em contexto precedente, ponto de articulação da consoante precedente e seguinte), as diferenças na constituição dos fatores dessas variáveis dificultaram comparações entre os resultados ou generalizações. Em nossa análise, conforme já destacamos, separamos o contexto precedente e seguinte pelo tipo e ponto de articulação dos sons; já os demais trabalhos adotaram formas diversas de agrupar e classificar esses contextos. 
Os resultados da variável tipo de consoante/vogal em contexto precedente, em nossa amostra, apontaram a vogal $-\mathrm{i}(0,83)$ e as consoantes nasais $(0,57)$ como favorecedores da elevação. Em relação ao ponto de articulação da consoante precedente, as consoantes labiodentais $(0,83)$ e as bilabiais $(0,64)$ favoreceram a elevação de /o/ para /u/.

A variável ponto de articulação da consoante seguinte apontou principalmente as consoantes pós-alveolares $(0,73)$ como favorecedoras da elevação. Em relação ao tipo de consoante/vogal seguinte, a elevação predominou com as consoantes fricativas $(0,66)$ e a vogal posterior média $(0,63)$; as vogais altas, ao contrário do esperado, desfavoreceram a elevação.

Quanto às variáveis sociais, os resultados parecem demostrar que o sexo feminino é mais sensível às normas de maior prestígio ou às inovações, pois as mulheres da amostra de Irati se mostraram mais favoráveis à elevação da vogal postônica final /o/ $(0,77)$; já os homens, com somente 0,27 para a elevação, favoreceram a preservação da vogal final /o/.

Os resultados mostram, ainda, que a etnia que mais favorece a elevação de /o/ átono final em Irati é a polonesa $(0,70)$; os híbridos apresentam um resultado próximo ao ponto neutro $(0,47)$ e os ucranianos desfavorecem a elevação $(0,36)$, favorecendo a preservação da vogal final /o/. Esses resultados parecem indicar que a manutenção ou não da cultura de origem estaria condicionando a preservação do /o/ final pelos descendentes de ucranianos e sua elevação para $/ \mathrm{u} /$ na fala dos descendentes de poloneses.

Em relação à escolaridade, os resultados mostram que não temos uma escala gradual decrescente nos pesos atribuídos aos diferentes níveis de escolaridade dos falantes, pois verificamos que o ensino médio favorece a elevação $(0,58)$, o fundamental II a desfavorece $(0,43)$ e o fundamental I apresenta um resultado no ponto neutro $(0,50)$. Esses resultados necessitam, portanto, de maiores refinamentos para se chegar a conclusões mais consistentes.

\section{Referências}

AguilerA, V. de A. Atlas Lingüístico do Paraná. Apresentação. Londrina: Editora da UEL, 1996.

BISOL, L. Neutralização das átonas. Revista Letras, Curitiba, n. 61 esp., p. 273-283, 2003.

BISOL, L. A Simetria no sistema vocálico do Português Brasileiro. Linguística, Porto, v. 5, p. 41-52, 2010.

CÂMARA JR., J. M. Estrutura da Lingua Portuguesa. 39. ed. Petrópolis: Vozes, 2004.

IBGE. Censo [município de Irati-PR]. Disponível em: <https://bit.ly/2MKLEkX>. Acesso em: 20 maio 2017a. 
IBGE. Histórico [município de Irati-PR]. 2016. Disponível em: $<$ https://bit.ly/2UF5aCr>. Acesso em: 20 maio 2017b.

LABOV, W. Padrões sociolinguísticos. Tradução de Marcos Bagno, Maria Marta Pereira Scherre, Caroline Rodrigues Cardoso. São Paulo: Parábola, 2008 [1972].

LIMA-HERNANDES, M. C. Sociolinguística e línguas de herança. In: MOLLICA, M. C.; FERRAREZI JR, C. (Org.). Sociolinguística, sociolinguísticas: uma introdução. São Paulo: Contexto, 2016. p. 97-110.

LIMEIRA, L. O não alçamento das vogais médias na fala de Curitiba sob a perspectiva da sociolinguística quantitativa. 2013. Dissertação (Mestrado em Letras) - Universidade Federal do Rio Grande do Sul, Porto Alegre.

LOREGIAN-PENKAL, L. et al. Banco de dados de fala eslava: discussões metodológicas. In: CAMPIGOTO, J.; CHICOSKI, R. (Org.). Brasil-Ucrânia: linguagem, cultura e identidade. São Paulo: Paco, 2013. p. 25-43.

LOREGIAN-PENKAL, L.; COSTA, L. Realização da vogal média anterior /e/ em posição postônica final: um estudo variacionista. In: SIMPÓSIO INTERNACIONAL DE ESTUDOS ESLAVOS, 4., 2016, Irati. Caderno de Anais... Irati: UNICENTRO, 2016. p. $474-487$.

MACHRY DA SILVA, S. Elevação das vogais médias átonas finais e não finais no português falado em Rincão Vermelho-RS. 2009. Dissertação (Mestrado em Letras) - Pontifícia Universidade Católica do Rio Grande do Sul, Porto Alegre.

MILESKI, I. A elevação das vogais médias átonas finais no português falado por descendentes de imigrantes poloneses em Vista Alegre do Prata-RS. 2013. Dissertação (Mestrado em Letras) Pontifícia Universidade Católica do Rio Grande do Sul, Porto Alegre.

VARLINFE. Banco de dados. Disponível em: <https://bit.ly/2Skqrns > .

VIEIRA, M. J. B. As vogais médias postônicas: uma análise variacionista. In: BISOL, L; BRESCANCINI, C. (Org.). Fonologia e variação: recortes do português brasileiro. Porto Alegre: EDIPUCRS, 2002. p. 127-259.

VIEIRA, M. J. B. As vogais médias átonas nas três capitais do sul do país. In: BISOL, L.; COLLISCHONN, G. (Org.). Português do Sul do Brasil: variação fonológica. Porto Alegre: EDIPUCRS, 2009. p. 50-72.

WEINREICH, U.; LABOV, W.; HERZOG, M. Fundamentos empiricos para uma teoria da mudança linguística. São Paulo: Parábola, 2006 [1968]. 